\title{
Effect of Built Environment on Health Dimensions during the Quarantine: A Cross-Sectional Study Following the Covid-19 Pandemic in Iran \\ Ali Sharghi $i^{1} \mathbb{D}$, Saeedeh Asadi ${ }^{2} \mathbb{D}$
}

Date of submission: 22 Aug. 2020 Date of acceptance: 31 Oct. 2020

\section{Original Article}

\begin{abstract}
INTRODUCTION: The imposition of quarantine in pandemics brings about negative psychological consequences. Sufficient understanding based on environmental and behavioral sciences leads to the prediction of needs and preparedness. Given the role of housing and the environment on health, awareness of their effects on the COVID-19 pandemic will facilitate future actions and risk management planning.

METHODS: The present cross-sectional exploratory study was conducted based on a mixedmethod approach. In the qualitative section, participants who were selected by non-probability sampling method were interviewed via phone, and data collection continued until data saturation using the snowball method. A number of 27 telephone interviews were conducted and after the content analysis of unorganized data, the questionnaire was developed in three parts, the initial pilot was conducted on 30 participants, and Cronbach's alpha was calculated at 0.76 . Moreover, 144 online questionnaires were completed in What'sApp virtual groups by purposive and available sampling method, followed by statistical analysis.

FINDINGS: As evidenced by the obtained results, in house and interior design scales, surface area; furniture; color; opening and outdoor space as well as living space and in neighborhood scale, density indicators; shared accesses and spaces have positively affected the tolerance of quarantine, reduction of anxiety, and health improvement. Furthermore, stress-reducing places were found to be different in different age groups. In addition, some motivations have generated some new behaviors and needs which are supported by such affordances as openings and windows to open spaces for the provision of natural daylight and ventilation, as well as a specific open space for movement, nature enjoyment, activity, physical activity, and contact with the natural environment.

CONCLUSION: There was a reciprocal relationship between behavioral orientations and environmental-physical aspects of housing in the current health crisis. The residential environment can influence disease prevention and the promotion of health-related behaviors.
\end{abstract}

Keywords: COVID-19; Health; Housing; Quarantine; Residential Environment.

How to cite this article: Sharghi A, Asadi S. Effect of Built Environment on Health Dimensions during the Quarantine: A Cross-Sectional Study Following the Covid-19 Pandemic in Iran. Sci J Rescue Relief 2020; 12(4): 242-53.

\section{Introduction}

$\mathrm{T}$ The recent decades have witnessed epidemics, large-scale pandemics, and emerging pathogens that have posed significant public health problems in the world (1). Evidence is accumulating that these events have increased over the past century and will persist due to increased global travel, urbanization, global interactions, and over-exploitation of natural resources $(2,3)$. Consequently, quarantine policy is recognized as one of the control strategies aimed at reducing the infection risks, Such as SARS and quarantine in Hong Kong, China (4), Toronto, Canada (5-7), H1N1 in Australia (8), Mers in South Korean (9), Ebola in Senegal and Sierra Leone $(10,11)$. In December 2019, a new strain of coronavirus rapidly spread across the world (12), and the World Health Organization

1. Associate Professor, Architecture and Urban Planning Faculty, Shahid Rajaee Teacher Training University, Lavizan, Tehran, Iran 2. PhD Candidate, Architecture and Urban Planning Faculty, Shahid Rajaee Teacher Training University, Lavizan, Tehran, Iran Correspondence to: Ali Sharghi, Email: sharghi@sru.ac.ir 
declared a public and international health emergency in January 2020 (13). Following this outbreak, numerous communities adopted such policies as public quarantine and social distancing.

Based on the prevailing agreement of epidemiologists, imposing quarantine is the key to the success of disease control in countries severely affected by COVID-19 (14). By definition, quarantine is the isolation of potentially at-risk individuals from others (6). It prevents the spread of infectious diseases by restricting activities, interaction, and daily routines $(15,16)$. Although this strategy helps control the spread of the disease (17), it is often unpleasant and brings about significant adverse effects for those who experience quarantine and isolation (18). The related studies pointed to the negative psychological consequences of this strategy, including confusion, anger (14), anxiety, distress, depression (6), as well as significant changes in lifestyle and behaviors (14). In addition, pandemics also cause changes in individual behaviors, such as Inactivity due to fear in places (19). Furthermore, disruption in the regularity of the routine of rest and activity exacerbates these adverse consequences (20) which persist for long $(18,21)$ and negatively affect other dimensions of health (14). Therefore, some strategies are required to reduce or prevent such consequences.

Apart from the direct effects of COVID-19 on the physical health of people, the other negative consequences of quarantine and disease have turned it into a disaster that calls for an unknown adversary (22). Being isolated and confined affects the individuals' psyche (23), and psychological stress affects the body's immune system (24). At the same time, the subsequent emotional reactions are the major motivation factor (5). Therefore, the problems and consequences which occur among communities during this period call for effective interventions and the improvement of people's well-being in high-risk communities (16). Moreover, in these circumstances, there is an increased need for planning to increase community health capacity (25). Furthermore, according to experts, mental health is of great importance in saving lives threatened by the pandemic and helping to maintain and rebuild society after the crisis (26). In recent years, there has been a growing awareness about the impact of the design and structure of built environments on lifestyle (27).
As indicated by researchers, in traumatic experiences, designers must understand the physical and psychological problems experienced by residents and prevent the creation of unwanted stressful environments which impede recovery and well-being $(28,29)$. Regarding the role of a built environment in disasters or the prevention of infectious diseases, the focus has shifted towards medical centers (30) and the morphology of urban public spaces (31) A large proportion of studies in the field of infectious diseases have focused on the development of new solutions in a built environment with the aim of disease prevention since they play a critical role in supporting health and reducing risk (32). The majority of these studies have addressed the issue based on the fact that disease prevention is closely associated with the patterns of activities and interaction and is influenced by spatial configuration (33). Although architectural and urban spaces are effective in controlling infectious pandemics, these outbreaks present some serious problems and challenges to designing and planning in different buildings and urban spaces (22). Therefore, the current pandemic has changed the built environment function and there is a need for further analysis (34). In this regard, Lee (2018) pointed to the knowledge gap in the recognition of human behavior on a small scale and housing to develop models of people-place interrelationship (35). The living environment is regarded as one of the main dimensions of the built environment with two internal and external aspects affecting human health (36). During quarantine, the residential place is considered a place with the most significant effect on health protection. In light of the aforementioned issues, the present study aimed to assess the experiences and environmental behaviors in the built environment during quarantine and determine the effective factors influencing the facilitation of quarantine and reduction of consequences from the perspective of behavioral sciences and health in Iran. The research question is what is the role of housing and the living environment in preventing COVID-19 pandemic and the physical and psychological consequences of quarantine.

\section{Methods}

The present cross-sectional exploratory study was conducted based on a mixed-method design. 
The study population included communities under voluntary quarantine in Iran between late March 2020 and April 6, 2020, following the COVID-19 pandemic. The research framework was developed in two main steps in accordance with the conditions and impossibility of a field survey.

The first step was performed based on a qualitative design that used telephone interviews, purposive sampling method, snowball and analytical approach, content analysis, and grounded theory. In order to identify the spatial experiences of individuals during home quarantine, the eligible individuals were interviewed via phone. The inclusion criteria entailed: 1) age> 18 years and 2) being under voluntary quarantine during the research period. The second phase of telephone interviews continued with the snowball sampling method, and the interviewees were asked to suggest other qualified individuals. A number of 37 semistructured in-depth interviews (19 females and 18 males within the age range of 20-76 years) were conducted, each lasting 45 min- $1 \mathrm{~h}$. The interviews continued until data saturation. Thereafter, the obtained data were coded in accordance with inductive content analysis, and finally, 236 concepts and 16 indicators were extracted. Subsequently, based on the existing theories, four main categories of research were developed using the grounded theory.

The second step; Based on the indicators and categories extracted in the qualitative step, the second step was conducted based on a quantitative approach. An online questionnaire was developed in three sections: a) demographic information and location of the respondent, $b$ ) assessing the mental condition and physical health of participants using the 6-item Kessler Psychological Distress Scale and two Likert-scale self-assessment questions, and c) Measurement of architecturalphysical parameters and environmental behavior. Moreover, at the end of the questionnaire, two open-ended questions were added to further explain the architectural-physical characteristics of housing and assess the health conditions during this period.

The data obtained in this phase were effective in a better understanding of results and responses. In total, the questions were designed in binary form (yes/no), Likert-scale, open-ended, and multiple choice. After the initial pilot on 30 people, the internal reliability was confirmed rendering a Cronbach's alpha of 0.76 . At this stage, a regional and volunteer purposive sampling was implemented. Based on the researchers' access to virtual channels and groups in different regions of Iran, the questionnaire was shared via What'sApp social network in virtual groups active in Tehran, Kerman, Gilan, Mazandaran, and Shiraz provinces, and individuals were asked to share it in other groups. Adequacy of sample size was also determined based on studies conducted in the field of quarantine.

In a study performed by Hawryluck et al. (2004), the psychological effects of quarantine on people were examined following the outbreak of SARS in Toronto, Canada. A number of 129 quarantined individuals were selected by convenience sampling and participated in the research using the web-based survey method (6). In another study in 2005, extensive experiences of quarantine following the Toronto SARS outbreak were examined using a mixed-method, telephone interviews, and a web-based questionnaire. The referred study was conducted on six focus groups and a total of 350 participants (5). Therefore, the adequacy of sample size was considered to be within the range of 129-350 subjects. A number of 573 online questionnaires were distributed, and the response rate was calculated at $25 \%$ due to sample attrition. Finally, 144 questionnaires were completed and submitted. The obtained data were analyzed using descriptive statistics, confirmatory factor analysis, t-test, and Pearson correlation coefficient.

\section{Findings}

Extraction of categories and indicators: Related categories and indicators were extracted by reviewing and analyzing the interviews. The following is a summary of interviews and notable data (Table 1).

The extracted categories are presented in Figure 1.

\section{Quantitative analysis}

Based on qualitative section findings, the relationship between indicators and categories was tested in the form of research hypotheses.

Hypothesis 1: Housing and residential environment affect the psychological well-being of communities during the quarantine.

Hypothesis 2: During quarantine, there is a greater tendency to engage in health behaviors in housing. 
Table 1. Content analysis of qualitative interviews

Residential density

Safe housing

population density

1 Shared uses at the neighborhood unit scale

Access spaces

Distress

Working space in the house Open space

2 Light and windows

Distress

Private spaces in the house Activity at home

Fear and insecurity

Contaminated spaces in the house Sick building syndrome

Health behavior in housing (ventilation of spaces) Distress

\section{Well-being in housing} Yard and garden

5

Outdoor health behavior (walking)

Ventilation and lighting through the opening)

Terrace and open spaces; Window and light

Public housing spaces

Sleep disorders (disorders in protective behaviors)

8 Color

Boredom in house

9 Area surface of the house

10 Physical activity

Social interaction
In this situation, all I can think about is that staying in this house, despite its 80 crowded housing units, was not the right and wise decision to do, and I have to look for a safe place for myself and my family. I feel my home is not safe and we may get infected too. The crowded residential complex is one of my concerns. When using the elevator, I get anxious that my little girl will not touch anything, the air inside will not be contaminated. It is not possible to use the stairs. When I get in the car, I am afraid of touching the handles, after getting in, I constantly spray alcohol on my hands and I am distressed.

If I could change my house in this situation, we would buy a house in a less crowded place; I would consider an office for my husband so that I would not have to keep the children quiet. I would make a terrace for playing and a place with more lighting and windows to ease the quarantine.

Every day after work, I immediately take a shower, go to the bedroom, and rest without eating anything. I try to be less active at home so that if I am infected with the coronavirus; my house will be less infectious contaminated.

I put the food I bought in a large basket right at the beginning of the entrance and my wife washes carefully. She cleans the floor with bleach several times a day. Occasionally I experience nausea, and headaches due to excessive use of detergents, disinfectants, and alcohol at home. I also have a history of allergies. I open the windows regularly to let fresh air into the house. On the other hand, I am afraid that the virus will enter the house through the outside air. Everything is unknown to us, and every day a new topic is announced about its transmission in virtual networks.

Although our house is old, it is good in this situation and we are used to staying at home. During the day, my wife and I care for the flowers, trees, and vegetables we have planted in our backyard. I walk in the yard to avoid heart problems and blood glucose. I also leave the doors and windows open for ventilation and sunlight during days.

The days are very hard for me. I only follow university classes online, watching people wander carelessly down the street. In my solitude, I listen to music and sleep. I have nothing more to do.

If I could change this apartment, I would add a terrace to spend time, drink tea, care for flowers and vases, and watch the outdoors, the people, and the park opposite. In the living room, I would install a window to the open space so that I could at least look out of the window or open it. Our window is on the patio. The living room is very depressing and the hours, days, and nights are the same. Since I do not go out much and I am not so active that I get tired, my night sleep is disturbed and this makes me nervous.

If I could change something in the house, I would choose bright wallpapers. I never thought dark colors are so depressing.

My large house has made it easier for children and grandchildren to stay with us.

Loneliness is hard for us. My father used to go to the park in the evenings even in the snow and rain. However, he has not left the house for a month now.

\begin{tabular}{|l|c|c|c|c|c|}
\hline Concepts & $\begin{array}{c}\text { Crowded } \\
\text { residential unit }\end{array}$ & $\begin{array}{c}\text { Opening the window } \\
\text { and fresh air }\end{array}$ & $\begin{array}{c}\text { boring Living } \\
\text { room }\end{array}$ & Three indicators \\
concepts
\end{tabular}

Figure 1. Research coding process (authors) 
Hypothesis 3: The interior design of houses is effective in various aspects of health during the quarantine.

Hypothesis 4: At the neighborhood unit scale, the residential environment design affects the health dimensions of the community during the quarantine.

\section{First hypothesis}

There is a complex and multidimensional relationship between housing and wellbeing, and numerous factors affect this relationship (37). In describing the effect of the built environment on mental well-being, Kostas referred to its impact on indirect and mental dimensions (38). In widespread events, such as disasters and pandemics, this concept changes since the mental health of the community is affected (39). In such situations, perceived stress from negative emotions and threats negatively affects various aspects of life and induces mental tension (40). Based on the results of the current study, the psychological well-being of the community can be affected by insecurity about contracting the disease at home and psychological distress caused by quarantine. Accordingly, the mentioned indicators were studied.

\section{Protection from the disease}

Phi coefficient and Cramer's coefficient of correlation were used to identify the role of home security in the prevention of COVID-19 disease. According to the findings, the majority of people consider their home a safe place for the prevention of COVID-19 disease. Moreover, the correlation coefficient between the two variables of home security and secondary safe places was
Table 2. Correlation coefficient between home security and in return for not knowing it secure

\begin{tabular}{ccc} 
& Value & Significance \\
\hline Phi & .419 & .193 \\
Cramer & .209 & .193 \\
n & 144 & \\
\hline
\end{tabular}

used to assess the tendency to find a secondary safe place from participant's insight, opposed to home security in this situation (Table 2). Based on the correlation coefficient, no significant relationship was detected between the two variables. Consequently, the individuals who did not deem their houses to be secure regarded a different place as a safe place

\section{Quarantine-induced psychological distress}

Based on the findings of the Kessler Psychological Distress Scale and respondents' self-assessment of their mental condition, the majority of the study participants suffer from some level of anxiety and stress. On the home scale, we can refer to the indicators of stress due to the possibility of contamination of spaces and staying at home for a long time. In the analysis of these parameters, those house spaces that cause anxiety and stress or reduce such tensions (Figure 2) were investigated. It was initially found that from a community point of view, the entrance is the most contaminated place in the house. Based on the results of the correlation test, there was no significant relationship between spaces with infection possibility and stressreducing places at home. On the other hand, a significant relationship was observed in different age groups (Table 3 ) in the assessment of stressreducing places at home.

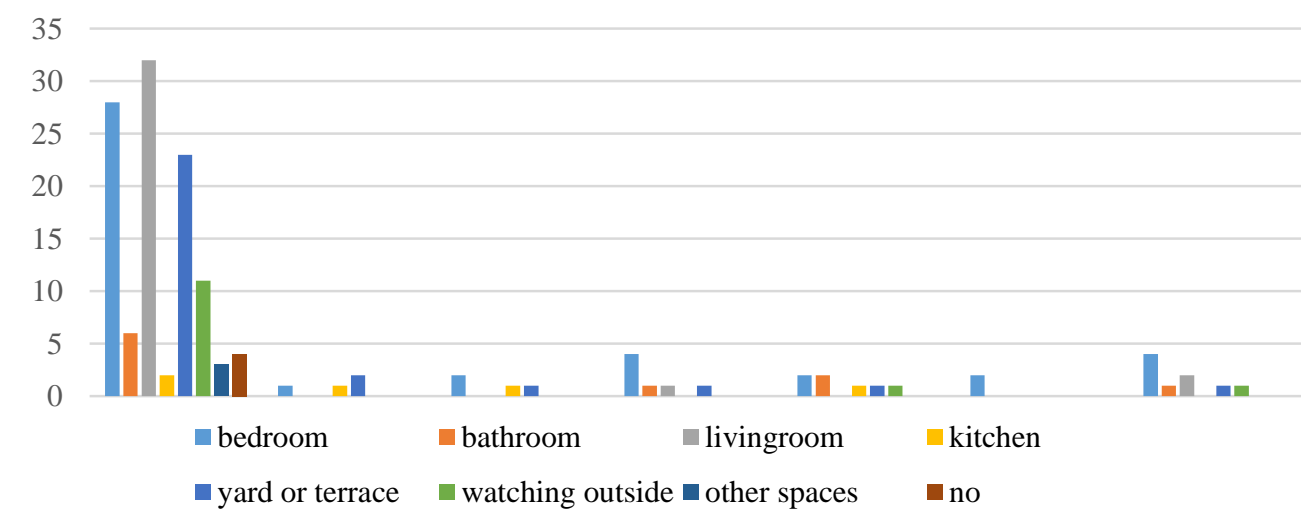

Figure 2. Frequency of spaces with the possibility of infectious contamination against spaces that reduce stress 
Table 3. Stress-reducing places at home in different age groups

\begin{tabular}{|cccc}
$\begin{array}{c}\text { Which spaces at home gives you more peace of mind } \\
\text { in the event of stress during quarantine? }\end{array}$ & $\begin{array}{c}\text { Chi-square } \\
\text { in }\end{array}$ & $\begin{array}{c}\text { Degrees of freedom } \\
\text { Significance level }\end{array}$ & .213 \\
\hline
\end{tabular}

Based on the findings, in the 20-25 age group, in case of distress and anxiety, the most widely used space is private places, such as the bedroom or another private space for sleeping, relaxation, and medication. In the 26-35 age group, private and public spaces, such as bedrooms and living room, had an equal contribution to the control of anxiety and distress. In addition, this age group prefers to use private open spaces, such as a yard or terrace. According to the findings, during anxiety and distress, people in the age range of 36-45 tend to spend their time outdoors or watching the scenery. In the age group of 46-55 years and older, the use of the living room, socializing with family members, and spending time in the terrace or yard (watching spring nature and using fresh air) had the highest priority, respectively. In the last two age groups, using the kitchen (distracting and doing housework) was also regarded as an option. It is noteworthy that no significant gender differences were observed in the mentioned categories and indicators.

\section{Second hypothesis}

Health behaviors can be regarded as purposeful activities and behaviors in line with self-concept or environment change so as to align with the intended behavior or self-concept. In this category, according to the findings obtained in the qualitative phase, three types of behaviors were identified. Some of these behaviors are exhibited due to such motivations as health care, deprivation of contact with natural outdoor environments, indoor air pollution, and sick building syndrome due to excessive use of detergents and disinfectants and there is a great tendency to do them. The following analyses were performed to identify significant differences in the emergence of these behaviors due to a long quarantine period, compared to previous circumstances.

\section{Physical activity in private open spaces}

Phi coefficient and Cramer's coefficient of correlation were used to examine the difference in this behavior (Table 4). Based on the results, there was a significant relationship between the exhibition of this behavior, as compared to before. Some motivations, such as physical activity, using fresh air, and spending time, were the most common reasons for this increase.

\section{Natural ventilation through openings}

Phi coefficient and Cramer's coefficient of correlation were used to investigate the difference in this behavior, as compared to before (Table 4). According to the analyses, there was a significant relationship between natural ventilation through openings and modification of this behavior during quarantine, compared to before. During the quarantine period, window opening-closing for natural ventilation is more frequently performed, as compared to before. The need for fresh air, reduction of internal contaminants, and prevention of disease transmission among family members are the major incentives to exhibit this behavior. On the other hand, this behavior is not displayed in relation to windows or openings that opened to shared spaces between other residential units, such as patios, and these openings are useless.

\section{Daylighting}

Phi coefficient and Cramer's coefficient of correlation were used to assess the relationship between the use of natural daylight, as compared to previous conditions in the house (Table 4). Based on the results, there is a significant correlation between the use of natural daylight and modification of this behavior during quarantine, and there is a stronger need for natural daylight more than before.

Table 4. Correlation between health behaviors and their alteration compared to before the quarantine

\begin{tabular}{cccc}
\hline Use of open spaces & Phi & Cramer's V & Significance level \\
Utilization of natural ventilation & 0.553 & 0.277 & 0.000 \\
Use of natural daylight & 0.548 & 0.274 & 0.000 \\
$\mathbf{n}$ & 0.566 & 0.283 & 0.000 \\
\hline
\end{tabular}


Table 5. Correlation between other living spaces color and preferred

\begin{tabular}{ccc} 
& Value & Significance level \\
Phi & .414 & .216 \\
Cramer's v & .207 & .216 \\
n & 144 & \\
\hline
\end{tabular}

\section{Third hypothesis}

One-sample t-test was used to assess the effect of the housing design and interior plan on tolerance of quarantine. Based on the calculation of mean and standard deviation, the mean obtained in the sample group exceeded the default value (Table 6). As illustrated by the results, this relationship is significant $(\mathrm{P}<0.05)$; consequently, housing design and interior plan have a significant impact on the tolerance of quarantine and its consequences. Furthermore, the role of related indicators in this scope has been investigated.

\section{Color}

Some issues, such as the importance of living spaces color and preferred color from the community insight were examined to assess the role of color in different spaces of the house in quarantine. According to the findings, the color of interior spaces contributes greatly to staying at home for a long time. Nevertheless, there was no significant correlation between the preferred color in other spaces of the house and the favorite color from the community insight (Table 5).

Private open spaces, windows, and openings that open onto the outside open spaces, using natural daylight, house area, and furniture: Figure 3 displays the importance of each of these indicators in quarantine conditions.

The Chi-square test was also used to investigate the differences between the options (Table 7). Based on the findings, the aforementioned indicators were considered statistically significant $(\mathrm{P}<0.05)$.

\section{Fourth hypothesis}

The one-sample t-test was used to examine the indicators of access spaces, population density, residential density, and shared living spaces affecting the design of residential places at the scale of neighborhood units. Based on mean and standard deviation, the mean obtained in the group exceeded the default value (3) (Table 6). A p-value less than 0.05 was considered statistically significant. In light of the obtained results, it can be concluded that the design of living space has a significant effect on the tolerance of quarantine and the resultant stress, as well as the prevention of disease outbreaks.

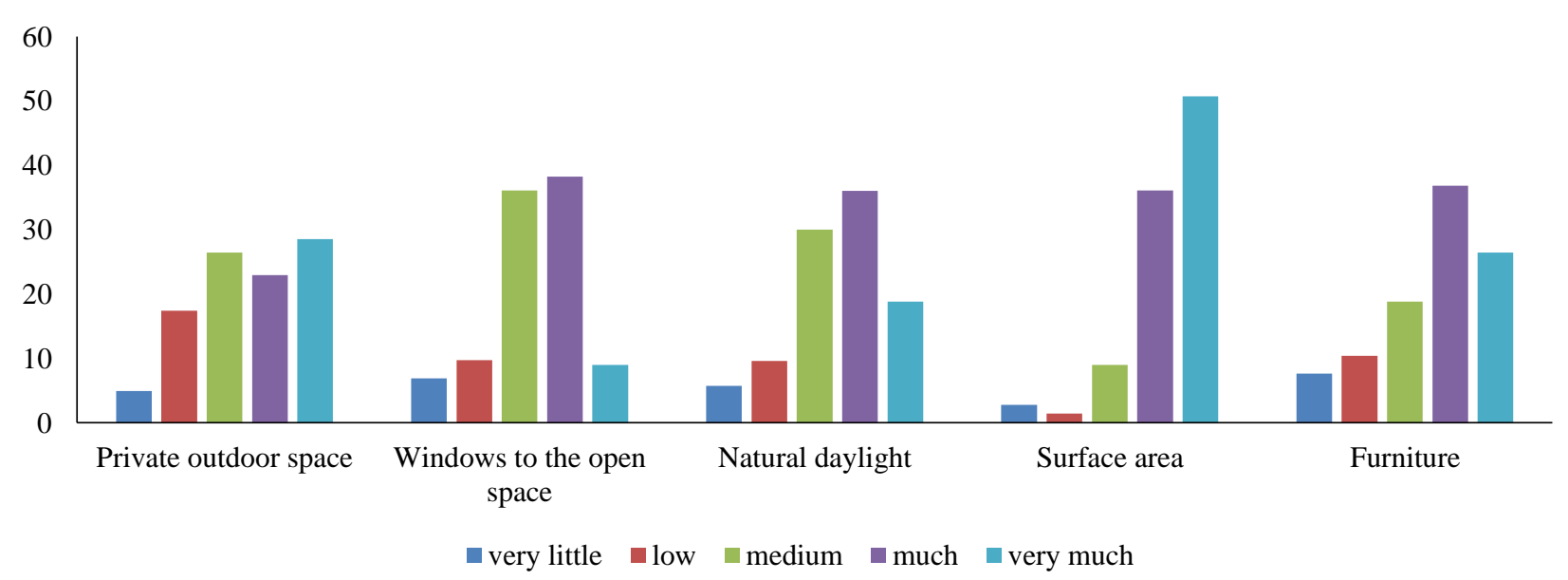

Figure 3. Importance percentage of private open space, window and opening, natural daylight, house area, and furniture

Table 6. Results of sample t-test test for the comparison of mean

\begin{tabular}{|c|c|c|c|c|c|c|}
\hline & \multicolumn{6}{|c|}{ Value $=3$} \\
\hline & $\mathbf{t}$ & $\begin{array}{l}\text { Degrees of } \\
\text { freedom }\end{array}$ & $\begin{array}{c}\text { Significance } \\
\text { level }\end{array}$ & $\begin{array}{c}\text { Mean } \\
\text { difference }\end{array}$ & $\begin{array}{l}95 \% \text { conf } \\
\text { Minimum }\end{array}$ & $\begin{array}{l}\text { lence level } \\
\text { Maximum }\end{array}$ \\
\hline Housing design and interior plan & -14.935 & 143 & .000 & -.53906 & -.6104 & -.4677 \\
\hline Residential layout & 24.873 & 143 & .000 & 1.28241 & 1.1805 & 1.3843 \\
\hline
\end{tabular}


Table 7. Chi-square test

\begin{tabular}{cccc|ccc} 
& $\begin{array}{c}\text { Private outdoor } \\
\text { space }\end{array}$ & $\begin{array}{c}\text { Windows to the } \\
\text { open space }\end{array}$ & $\begin{array}{c}\text { Natural } \\
\text { daylight }\end{array}$ & Surface area & Furniture \\
\hline $\begin{array}{c}\text { Chi-square } \\
\text { Degrees of freedom }\end{array}$ & $25.722 \mathrm{a}$ & $71.069 \mathrm{a}$ & $48.431 \mathrm{a}$ & $141.486 \mathrm{a}$ & $41.000 \mathrm{a}$ \\
Significance level & 4 & 4 & 4 & 4 & 4 \\
\hline
\end{tabular}

\section{Discussion and Conclusion}

Although community quarantine (the general stay-at-home policy) and Minimizing household size are indispensable for the prevention of COVID-19 transmission (41), researchers have highlighted that COVID-19 prevention should not increase risk in other aspects of health (23). In this regard, staying at home for too long and inactivity pose serious risks to health and increase anxiety and distress. Moreover, in such crises, relevant studies are scattered, and little attention is devoted to their long-term effects on health (42). During a disease outbreak, houses are not destructed similar to other disasters, rather structures and processes that interconnect and coexist with the environment are disrupted. In this regard, it is essential to understand the interconnection of spatial-social aspects in quarantine since this strategy is realized in completely spatial circumstances (43). Therefore, as Xie (2019) emphasizes the role of housing quality in health (44), some qualities of housing and residential environments, such as interior plan and living space design, are effective in the prevention of disease, reduction of negative physical and psychological consequences of quarantine, and promotion of community health behaviors. In this regard, Amerio et al. (2020) emphasized that in the post-corona virus era, housing design strategies should focus on larger and more livable spaces (45). In addition, according to the literature high-density housing (46), indoor air quality (47), walkability (27), access to green spaces and natural landscape $(48,49)$, lighting quality (50), and physical activity in the environment (51), affect the disease prevention, health, and wellbeing. In the present study, on house scale; surface area, furniture, opening and window, private open space, the color of spaces, and access to natural daylight, and on the neighborhood scale, shared access spaces, such as stairs and elevators, population density, and residential density and shared spaces were the effective factors on quarantine-induced distress and improving well-being.
Furthermore, the importance of a safe and secure environment from a health care perspective should not be underestimated (30). According to the findings, during quarantine, the living place plays a peculiar role in preventing infection and reducing stress. Although the previously conducted studies pointed to a higher level of anxiety and distress among women in crisis (52), in the present study such a gender difference was not observed in interaction with the built environment in quarantine and its consequences. Alteration in living conditions affects people's behaviors. In terms of health behavior support, it is believed that the physical and social environment should be taken into account in public health interventions in order to promote health and health-related behaviors (53). In fact, these environmental policies and interventions are of utmost importance in influencing health behaviors. Emphasizing the importance of context, scientists describe human behavior as people-environment interaction (55), and the main hypothesis of ecological theory is based on the determining role of environmental factors on behavior (56). Therefore, the living environment makes a great contribution to the promotion of health behaviors (56) and lifestyle (57) since it encourages people to active participation through its passive potentials, such as the quality of the indoor environment or the impact on healthrelated behaviors (58). Quarantine also creates behaviors and needs that require capabilities in the environment and special qualities of housing.

Staying at home has been found to cause sleep disorders and physical health problems. On the contrary, other needs with different motivations are created in society. Firstly, windows and openings are of paramount importance for natural daylight benefits, watching outside landscape, and benefiting from sunlight disinfection properties. Exposure to sunlight is a major principle among health professionals (59), and according to the literature, its deprivation brings about psychological effects at the emotional level (60). Therefore, the positive effects of sunlight on 
mental health, health behavior, and generation of positive energy are undeniable (61). Moreover, the most marked relationship between daylight and human beings is the regulation of the circadian biological clock and the related functions (62) which leads to a significant improvement in the quality of life, efficiency, and sleep $(63,64)$. In addition, light is effective in reducing and controlling indoor infectious contamination (65). The second dimension highlights health behaviors by increasing the frequency of ventilation by opening windows during the quarantine. The notable incentives include natural ventilation, using fresh spring air, and reduced likelihood of disease transmission among family members. There is ample evidence on the association of ventilation, airflow in buildings, with the prevention and control of the spread of infectious diseases (66), such as COVID-19 among residents (67). On a final note, the need for private outdoor space for physical activity, spending time, and enjoying the natural environment has been observed in the third dimension of health behavior since the interaction and activity limitations of the community during the pandemic have created the need and desire for activity in residential environments more than before. As illustrated by related research, exposure to natural environments helps to improve cognitive and mental health (68), increase physical activity, and reduce psychological stress (69). Therefore, the presence of green space in the residential environment and contact with it significantly contributes to health.

The present study assessed the psychological consequences of quarantine and the role of housing and residential environment quality on the Iranian affected communities' health in the COVID-19 pandemic. The research is based on the fact that awareness of the interaction of housing and health during quarantine, as well as the understanding of the consequences, needs, and behaviors in such conditions, will lead to better preparedness, planning, and adaptability of communities. According to the findings, longterm isolation and inactivity due to quarantine and concern about the disease have caused anxiety, fear, and stress. Furthermore, boredom and inactivity due to disruption in daily routine pose daunting challenges to health and functional balance which result in negative consequences in the long term. The present study pointed to the effects of housing location, the physicalenvironmental characteristics of housing, and the neighborhood unit on these outcomes. According to the general results, housing and residential environments exert direct and indirect impacts on the well-being of communities in the current health crisis circumstances and quarantine from two dimensions of physical and mental health.

The results of the present study indicated that at house scale, housing plan and interior design, surface area, furniture, the color of spaces, opening, and in neighborhood scale, population density, accesses, and shared spaces in the residential unit positively affected the tolerance of quarantine. In the communities under study, fear of infection has caused anxiety and stress, which have emerged in the form of infectious contaminated spaces in housing and residential environment and a sense of security in preventing infection. This concern has been expressed in the use of house entrance with more probability of infectious contamination and as a barrier between the indoor and outdoor environment, access spaces, shared spaces, and density on a unit neighborhood scale. In such circumstances, home is a safe place for the prevention of infection, as well as the reduction of distress and anxiety. In conditions of stress, different age groups select different spaces in the house as special spatial territories for the revision of peace of mind. The younger age groups were inclined to spatial activity in private housing spaces, while in older age groups this tendency was towards more public spaces and private open spaces. In addition, some motivations during this period have led to the emergence of behaviors and physicalenvironmental needs in housing, compared to before. These new needs include access to open space for sunlight exposure, ventilation, private open space for physical activity, contact with nature, and spending time. Therefore, it can be concluded that behavioral approaches and physical-environmental dimensions of housing and the residential environment have a reciprocal association in the global crisis of the COVID-19 pandemic. Therefore, in the current situation of public health urgency and the need for quarantine, some environmental affordance and qualities can control disease transmission and provide health and well-being. Moreover, they support the special needs and behaviors in these conditions; thereby, alleviating the physical and psychological 
consequences of quarantine.

\section{Acknowledgments}

This work was supported by Shahid Rajaee Teacher Training University under contract number 6136 dated 15 July 2020, accordingly thanks to the university's research management

\section{Conflict of Interests}

Authors have no conflict of interests.

\section{References}

1. Srinivasa Rao AS, Vazquez JA. Identification of COVID-19 can be quicker through artificial intelligence framework using a mobile phone-based survey when cities and towns are under quarantine. Infect Control Hosp Epidemiol 2020; 41: 826-30.

2. Jones KE, Patel NG, Levy MA, Storeygard A, Balk $\mathrm{D}$, Gittleman JL, et al. Global trends in emerging infectious diseases. Nature 2008; 451(7181): 990-3.

3. Morse SS. Factors in the emergence of infectious diseases. Plagues and politics. London: Palgrave Macmillan; 2001.

4. Lee S, Chan LY, Chau AM, Kwok KP, Kleinman A. The experience of SARS-related stigma at Amoy Gardens. Soc Sci Med 2005; 61(9): 2038-46.

5. DiGiovanni C, Conley J, Chiu D, Zaborski J. Factors influencing compliance with quarantine in Toronto during the 2003 SARS outbreak. Biosecurity Bioterrorism 2004; 2(4): 265-72.

6. Hawryluck L, Gold WL, Robinson S, Pogorski S, Galea S, Styra R. SARS control and psychological effects of quarantine, Toronto, Canada. Emerg Infect Dis 2004; 10(7): 1206.

7. Blendon RJ, Benson JM, DesRoches CM, Raleigh $\mathrm{E}$, Taylor-Clark K. The public's response to severe acute respiratory syndrome in Toronto and the United States. Clin Infect Dis 2004; 38(7): 925-31.

8. Braunack-Mayer A, Tooher R, Collins JE, Street JM, Marshall H. Understanding the school community's response to school closures during the H1N1 2009 influenza pandemic. BMC Public Health 2013; 13(1): 344.

9. Jeong H, Yim HW, Song YJ, Ki M, Min JA, Cho J, et al. Mental health status of people isolated due to Middle East Respiratory Syndrome. Epidemiol Health 2016; 38: e2016048.

10. Caleo G, Duncombe J, Jephcott F, Lokuge K, Mills C, Looijen E, et al. The factors affecting household transmission dynamics and community compliance with Ebola control measures: a mixed-methods study in a rural village in Sierra Leone. BMC Public Health 2018; 18(1): 1-3.

11. Desclaux A, Badji D, Ndione AG, Sow K. Accepted monitoring or endured quarantine? Ebola contacts' perceptions in Senegal. Soc Sci Med 2017; 178: 38-45.

12. World Health Organization. Report of the WHOChina joint mission on coronavirus disease 2019 (COVID-19). Geneva: World Health Organization; 2020.

13. World Health Organization. Mental health and psychosocial considerations during the COVID-19 outbreak, 18 March 2020. Geneva: World Health Organization; 2020.

14. Jiménez-Pavón D, Carbonell-Baeza A, Lavie CJ. Physical exercise as therapy to fight against the mental and physical consequences of COVID-19 quarantine: Special focus in older people. Progr Cardiovasc Dis 2020; 63: 386-8.

15. Centers for Disease Control and Prevention. Quarantine and isolation. Georgia: Centers for Disease Control and Prevention; 2017.

16. Hossain MM, Sultana A, Purohit N. Mental health outcomes of quarantine and isolation for infection prevention: a systematic umbrella review of the global evidence. Epidemiol Health 2020; 17: e2020038.

17. Day T, Park A, Madras N, Gumel A, Wu J. When is quarantine a useful control strategy for emerging infectious diseases? Am J Epidemiol 2006; 163(5): 479-85.

18. Brooks SK, Webster RK, Smith LE, Woodland L, Wessely S, Greenberg N, et al. The psychological impact of quarantine and how to reduce it: rapid review of the evidence. Lancet 2020; 395(10227): 912-20.

19. Madhav N, Oppenheim B, Gallivan M, Mulembakani P, Rubin E, Wolfe N. Pandemics: risks, impacts, and mitigation. disease control priorities. $3^{\text {rd }}$ ed. Washington, DC: Improving Health and Reducing Poverty Published; 2017.

20. Fiese BH, Tomcho TJ, Douglas M, Josephs K, Poltrock S, Baker T. A review of 50 years of research on naturally occurring family routines and rituals: cause for celebration? J Fam Psychol 2002; 16(4): 381-90.

21. Cava MA, Fay KE, Beanlands HJ, McCay EA, Wignall R. Risk perception and compliance with quarantine during the SARS outbreak. J Nurs Scholarsh 2005; 37(4): 343-7.

22. Megahed NA, Ghoneim EM. Antivirus-built environment: Lessons learned from Covid-19 pandemic. Sustain Cities Soc 2020; 61: 102350.

23. Jurak G, Morrison SA, Leskošek B, Kovač M, Hadžić V, Vodičar J, et al. Physical activity recommendations during the COVID-19 virus outbreak. J Sport Health Sci 2020; 9(4): 325-7.

24. Schmitt DA, Schaffar L. Confinement and immune function. Advances in space biology and medicine. Amsterdam, Netherlands: Elsevier; 1993. P. 229-35.

25. Lederberg J, Hamburg MA, Smolinski MS. 
Microbial threats to health: emergence, detection, and response. Washington, D.C: National Academies Press; 2003.

26. da Silva AG, Miranda DM, Diaz AP, Teles AL, Malloy-Diniz LF, Palha AP. Mental health: why it still matters in the midst of a pandemic. Braz $\mathbf{J}$ Psychiatry 2020; 42(3): 229-31.

27. Australian Institute of Health and Welfare. Health and the environment: a compilation of evidence. Australia: Australian Institute of Health and Welfare; 2011.

28. Dekel S, Ein-Dor T, Solomon Z. Posttraumatic growth and posttraumatic distress: a longitudinal study. Psychol Trauma 2012; 4(1): 94-101.

29. Substance Abuse and Mental Health Services Administration. SAMHSA's concept of trauma and guidance for a trauma-informed approach. Washington, D.C: HHS Publication; 2014.

30. Department of Health. The Health and social care act 2008: code of practice on the prevention and control of infections and related guidance. London: Department of Health; 2015.

31. Lak A, Asl SS, Maher A. Resilient urban form to pandemics: lessons from COVID-19. Med J Islam Repub Iran 2020; 34: 71.

32. Pinheiro MD, Luís NC. COVID-19 could leverage a sustainable built environment. Sustainability 2020; 12(14): 5863.

33. Sample H. Emergency urbanism and preventive architecture. Imperfect health: the medicalization of architecture. Canada: Canadian Centre for Architecture; 2012. P. 231-50.

34. Honey-Roses J, Anguelovski I, Bohigas J, Chireh V, Daher C, Konijnendijk C, et al. The impact of COVID-19 on public space: a review of the emerging questions. Cities Health 2020; In Press.

35. National Academies of Sciences, Engineering, and Medicine. Urbanization and slums: infectious diseases in the built environment, proceedings of a workshop. Washington, DC: The National Academies Press; 2018.

36. Howden-Chapman P. Housing standards: a glossary of housing and health. J Epidemiol Community Health 2004; 58(3): 162-8.

37. Janahi H, Raman S, Zapata-Lancaster MG. Understanding the impact of residential built environment design on inhabitants' wellbeing. ARCC Conference Repository, Philadelphia, USA; 2018.

38. Mouratidis K. Built environment and social wellbeing: How does urban form affect social life and personal relationships? Cities 2018; 74: 7-20.

39. Collins AE. Disaster and development. London: Routledge; 2009.

40. Gellman MD, Turner JR. Encyclopedia of behavioral medicine. New York: Springer; 2013.

41. Sjödin H, Wilder-Smith A, Osman S, Farooq Z,
Rocklöv J. Only strict quarantine measures can curb the coronavirus disease (COVID-19) outbreak in Italy, 2020. Eurosurveillance 2020; 25(13): 2000280.

42. Cook A, Watson J, Van Buynder P, Robertson A, Weinstein P. 10th Anniversary Review: Natural disasters and their long-term impacts on the health of communities. J Environ Monitor 2008; 10(2): $167-75$.

43. Kammerbauer M. Corona and the built environment. Available at: URL: https://www.toposmagazine. com/corona-and-the-built-environment/; 2020.

44. Xie S. Quality matters: housing and the mental health of rural migrants in urban China. Housing Stud 2019; 34(9): 1422-44.

45. Amerio A, Brambilla A, Morganti A, Aguglia A, Bianchi D, Santi F, et al. Covid-19 lockdown: housing built environment's effects on mental health. Int J Environ Res Public Health 2020; 17(16): 5973

46. Robinson E, Adams RM. Housing stress and the mental health and wellbeing of families. Victoria, Australia: Australian Institute of Family Studies; 2008.

47. Burge PS. Sick building syndrome. Occup Environ Med 2004; 61(2): 185-90.

48. Van den Berg M, Wendel-Vos W, van Poppel M, Kemper $\mathrm{H}$, van Mechelen W, Maas J. Health benefits of green spaces in the living environment: a systematic review of epidemiological studies. Urban Forestry Urban Green 2015; 14(4): 806-16.

49. Thompson Coon J, Boddy K, Stein K, Whear R, Barton J, Depledge MH. Does participating in physical activity in outdoor natural environments have a greater effect on physical and mental wellbeing than physical activity indoors? A systematic review. Environ Sci Technol 2011; 45(5): 1761-72.

50. Bluyssen PM. The indoor environment handbook: how to make buildings healthy and comfortable. London: Routledge; 2009.

51. Horve PF, Lloyd S, Mhuireach GA, Dietz L, Fretz $\mathrm{M}$, MacCrone $\mathrm{G}$, et al. Building upon current knowledge and techniques of indoor microbiology to construct the next era of theory into microorganisms, health, and the built environment. J Exp Sci Environ Epidemiol 2020; 30(2): 219-35.

52. MacGregor S. A stranger silence still: the need for feminist social research on climate change. Sociolog Rev 2009; 57(2 Suppl): 124-40.

53. Brug J, van Dale D, Lanting L, Kremers S, Veenhof C, Leurs M, et al. Towards evidence-based, qualitycontrolled health promotion: the Dutch recognition system for health promotion interventions. Health Educ Res 2010; 25(6): 1100-6.

54. Stokols D. The paradox of environmental psychology. Am Psychol 1995; 50(10): 821. 
55. Akintunde EA. Theories and concepts for human behavior in environmental preservation. J Environ Sci Public Health 2017; 1(2): 120-33.

56. Travert AS, Sidney Annerstedt K, Daivadanam M. Built environment and health behaviors: deconstructing the black box of interactions-a review of reviews. Int J Environ Res Public Health 2019; 16(8): 1454.

57. Sarkar C, Webster C, Gallacher J. Healthy cities: public health through urban planning. Cheltenham, UK: Edward Elgar Publishing; 2014.

58. Pinter-Wollman N, Jelić A, Wells NM. The impact of the built environment on health behaviours and disease transmission in social systems. Philosophical Transactions Royal Soc B Biol Sci 2018; 373(1753): 20170245.

59. Boubekri M, Cheung IN, Reid KJ, Wang CH, Zee PC. Impact of windows and daylight exposure on overall health and sleep quality of office workers: a case-control pilot study. J Clin Sleep Med 2014; 10(6): 603-11.

60. UK Green Building Council. Healthy homes, daylight and sunlight, technical paper. London, UK: Green Building Council; 2017.

61. Akbari S, Noori R. The status of light and color in environmental psychology in designing childfocused treatment spaces case study: Mofid pediatrics hospital. Armanshahr Architect Urban Dev 2014; 7(12): 45-53.

62. Martín-Olalla JM. The long term impact of Daylight Saving Time regulations in daily life at several circles of latitude. Sci Rep 2019; 9(1): 1-3.
63. Boubekri M, Cheung IN, Reid KJ, Wang CH, Zee PC. Impact of windows and daylight exposure on overall health and sleep quality of office workers: a case-control pilot study. J Clin Sleep Med 2014; 10(6): 603-11.

64. Elzeyadi I. Daylighting-bias and biophilia: quantifying the impact of daylighting on occupants health. London, UK: Green Building Council; 2011.

65. Fahimipour AK, Hartmann EM, Siemens A, Kline J, Levin DA, Wilson $\mathrm{H}$, et al. Daylight exposure modulates bacterial communities associated with household dust. Microbiome 2018; 6(1): 1-3.

66. Li Y, Leung GM, Tang JW, Yang X, Chao CY, Lin $\mathrm{JZ}$, et al. Role of ventilation in airborne transmission of infectious agents in the built environment-a multidisciplinary systematic review. Indoor Air 2007; 17(1): 2-18.

67. Dietz L, Horve PF, Coil DA, Fretz M, Eisen JA, Van Den Wymelenberg K. 2019 novel coronavirus (COVID-19) pandemic: Built environment considerations to reduce transmission. Msystems 2020; 5(2): e00245.

68. James P, Banay RF, Hart JE, Laden F. A review of the health benefits of greenness. Curr Epidemiol Rep 2015; 2(2): 131-42.

69. Dadvand P, Nieuwenhuijsen MJ, Esnaola M, Forns J, Basagaña X, Alvarez-Pedrerol M, et al. Green spaces and cognitive development in primary schoolchildren. Proc Nat Acad Sci 2015; 112(26): 7937-42. 